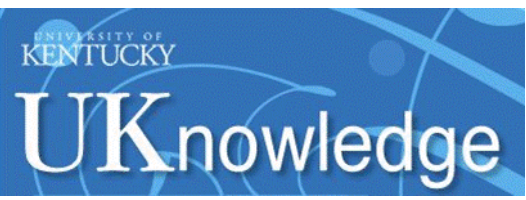

University of Kentucky

UKnowledge

Pharmacology and Nutritional Sciences Faculty

Publications

Pharmacology and Nutritional Sciences

$9-15-2017$

\title{
The 9th Conference on Metal Toxicity and Carcinogenesis: The Conference Overview
}

\author{
James T. F. Wise \\ University of Kentucky, jamestwise@uky.edu \\ Lei Wang \\ University of Kentucky, Iwa232@uky.edu \\ Zhuo Zhang \\ University of Kentucky, zhuo.zhang@uky.edu \\ Xianglin Shi \\ University of Kentucky,xshi5@email.uky.edu
}

Follow this and additional works at: https://uknowledge.uky.edu/pharmacol_facpub

Part of the Pharmacology, Toxicology and Environmental Health Commons

Right click to open a feedback form in a new tab to let us know how this document benefits you.

\section{Repository Citation}

Wise, James T. F.; Wang, Lei; Zhang, Zhuo; and Shi, Xianglin, "The 9th Conference on Metal Toxicity and Carcinogenesis: The Conference Overview" (2017). Pharmacology and Nutritional Sciences Faculty Publications. 89.

https://uknowledge.uky.edu/pharmacol_facpub/89

This Article is brought to you for free and open access by the Pharmacology and Nutritional Sciences at UKnowledge. It has been accepted for inclusion in Pharmacology and Nutritional Sciences Faculty Publications by an authorized administrator of UKnowledge. For more information, please contact UKnowledge@lsv.uky.edu. 


\section{The 9th Conference on Metal Toxicity and Carcinogenesis: The Conference Overview}

\section{Digital Object Identifier (DOI)}

https://doi.org/10.1016/j.taap.2017.04.007

Notes/Citation Information

Published in Toxicology and Applied Pharmacology, v. 331, p. 1-5.

(c) 2017 Elsevier Inc. All rights reserved.

This manuscript version is made available under the CC-BY-NC-ND 4.0 license https://creativecommons.org/licenses/by-nc-nd/4.0/.

The document available for download is the author's post-peer-review final draft of the article. 
Published in final edited form as:

Toxicol Appl Pharmacol. 2017 September 15; 331: 1-5. doi:10.1016/j.taap.2017.04.007.

\title{
The 9th Conference on Metal Toxicity and Carcinogenesis: The Conference Overview
}

\author{
James T. F. Wise ${ }^{\mathrm{a}}$, Lei Wang ${ }^{\mathrm{b}, \mathrm{c}}$, Zhuo Zhang ${ }^{\mathrm{c}}$, and Xianglin Shi ${ }^{\mathrm{a}, \mathrm{b}, \mathrm{c}}$ \\ aDivison of Nutritional Sciences, Pharmacology and Nutritional Sciences, College of Medicine, \\ University of Kentucky, Lexington, KY 40536, USA \\ bCenter for Research on Environmental Disease, College of Medicine, University of Kentucky, \\ Lexington, KY 40536, USA \\ 'Toxicology and Cancer Biology, College of Medicine, University of Kentucky, Lexington, KY \\ 40536, USA
}

\begin{abstract}
Heavy metals, such as arsenic, chromium, cadmium, nickel, mercury, and uranium are known to cause many human diseases and health complications after occupational or environmental exposure. Consequently, metals are environmental health concerns. This manuscript is an overview of the 9th Conference on Metal Toxicity and Carcinogenesis held in October 2016 in Lexington, Kentucky. Since 2000, this biennial meeting brings together experts in the field to discuss current and prospective research in an effort to advance research pertaining to metal toxicity and carcinogenesis. In this review we summarize the major topics discussed and provide insight regarding current research in the field and an account of the direction in which the field is progressing.
\end{abstract}

\section{Keywords}

metals; carcinogenesis; toxicity; conference

\section{Introduction}

Metal-induced diseases are significant public health concerns. Exposure to heavy metals occurs from both environmental and occupational sources (Fay et al., 2005; Chou et al., 2007; Beyersmann and Hartwig, 2008; Koedrith and Seo, 2011; Faroon et al., 2012; Wilbur et al., 2012). Metals of particular concern include, but are not limited to: arsenic, chromium,

\footnotetext{
Address correspondence to: Xianglin Shi, PhD, Center for Research on Environmental Disease, 1095 V.A. Drive, 306 Health Sciences Research Building, Lexington, KY 40536 USA., Telephone: (859) 257-4054, Fax: (859) 323-1059, xshi5@uky.edu.

The authors declare they have no actual or potential competing financial interests.

Conflict of Interest

The authors declare no conflicts of interest.

Publisher's Disclaimer: This is a PDF file of an unedited manuscript that has been accepted for publication. As a service to our customers we are providing this early version of the manuscript. The manuscript will undergo copyediting, typesetting, and review of the resulting proof before it is published in its final citable form. Please note that during the production process errors may be discovered which could affect the content, and all legal disclaimers that apply to the journal pertain.
} 
cadmium, nickel, mercury, and uranium. The conference on metal toxicity and carcinogenesis has been held biennially since 2000 (Wang and Shi, 2001; Leonard et al., 2004; Bower et al., 2005; Zhou et al., 2015), with about 100 scientists, including both national and international scientists, in attendance for the $9^{\text {th }}$ Conference in Lexington, Kentucky in October 2016. Presentations focused on a variety of research concerns and recent findings, which will undoubtedly stimulate additional research in the field of metal toxicity and carcinogenesis. Attendees included staff, students, post-doctoral fellows, faculty, along with government, and industry scientists. There were four scientific sessions encompassing major areas of research in the field: 1) Mechanisms of Metal Carcinogenesis, 2) Metal-Induced Toxicity and Disease, 3) Air Pollution of Metal Particles and Health, and 4) Epigenetic Mechanisms of Metal Carcinogenesis. There was also a poster session and a session on career development in environmental health sciences. There were eleven travel awards were awarded to both students and post-doctoral fellows during the conference.

In this conference overview, we will highlight the major research ideas presented at the meeting and how these areas integrate. We discuss topics that are new to the area and have a potential for growth, and highlight key research topics that require additional investigation within the field of metal toxicity and carcinogenesis. A special issue in the journal Toxicology and Applied Pharmacology documents some of these topics discussed during the conference.

\section{Recent Research Discoveries}

\section{Mechanisms of Metal Carcinogenesis}

While it is well known that some metals cause cancer and other diseases, most mechanisms of metal-induced carcinogenesis are not clearly understood (Wise et al., 2008; Wang L, et al., 2016). The oral and the poster sessions highlighted some overarching mechanisms of metal-induced carcinogenesis: oxidative stress, DNA damage and repair, generation/function of stem cells, autophagy, and epigenetics. These areas will be discussed briefly below. An observation was expressed that, within the metals settings, knowledge-based pathway mapping would be a powerful approach to expand our understanding of pathway interactions and cross-talk for this field.

Oxidative Stress-Considering all of the mechanisms discussed, oxidative stress clearly plays a key role in metal-induced carcinogenesis. Oxidative stress affects multiple processes in metal-induced carcinogenesis, such as autophagy, angiogenesis, inflammation, cancer stem cells, epigenetic alterations, metabolic reprogramming, and genetic instability (Wang L, et al., 2016). During early stage metal-induced carcinogenesis, the transformation of normal cells to malignant cells, high levels of free radicals are generated. During this process, oxidative stress has been demonstrated to play an important role. During the late stages of metal-induced carcinogenesis, malignantly transformed cells form tumors and exhibit decreased levels of oxidative stress, which promotes the tumorigenesis process. Once the cells are malignantly transformed, the capability of these transformed cells to generate free radicals and to cause oxidative stress is sharply reduced, leading to apoptosis resistance. However, these transformed cells also exhibit autophagy dysfunction, apoptosis resistance 
(which is linked to a low level of free radicals), inflammation with constitutively activated Nrf2 (Wang L, et al., 2016). This constitutively activated Nrf2 has been identified as one of the underlying mechanisms (Son et al., 2014) that maintain tumorigenesis. Zhuo Zhang (University of Kentucky) and Donna Zhang (University of Arizona) further highlighted these changes in free radical and Nrf2 levels during their presentations.

DNA Damage and Repair-DNA damage and repair is a major mechanism of environmentally-induced metal carcinogenesis (Wise et al., 2008). Several groups detected DNA double-stranded breaks produced by carcinogenic metals. It has been reported that hexavalent chromium $(\mathrm{Cr}(\mathrm{VI}))$ induced DNA double strand breaks are influenced by vitamin $\mathrm{C}$ and that these breaks are distributed non-randomly in nucleus (Anatoly Zhitovich, Brown University). Changes in DNA damage repair are a key process in metal-induced carcinogenesis (Wise et al., 2008; Wang L, et al., 2016). Multiple presentations discussed the role of DNA repair in metal-induced health concerns. John Wise, Sr. (University of Louisville) discussed the role of the DNA repair protein, RAD51, with $\mathrm{Cr}(\mathrm{VI})$ exposure. He presented evidence that $\mathrm{Cr}(\mathrm{VI})$ may interact with RAD51 and outlined future studies his group is planning to dowith $\mathrm{Cr}(\mathrm{VI})$ and DNA repair. Wei Dai (New York University School of Medicine) presented information that exposure to metals influence the sumoylation of Mus81, an endonuclease involved in homologous recombination repair. Meanwhile, Yinsheng Wang (University of California) revealed that arsenic compromises the functions of RING finger proteins important for genomic stability. These data are consistent with the report that arsenic binds zinc finger DNA repair proteins, and subsequently disrupts the proper function of these proteins, leading to increased zinc finger protein oxidation/ nitrosation (Ke Jian Liu, University of New Mexico).

The mechanisms of DNA damage and repair are not limited to chromium and arsenic, but also other metals of health concern. Astrid Engel (Tulane University) presented updates on their research involving the DNA damage repair response in human cells following exposure to nickel or cadmium and how L1 transposable elements play a role in these mechanisms.

Stem Cells-Metal-induced cancer stem cells have been one of most alluring fields in metal carcinogenesis (Wang et al., 2012). Erik Tokar (National Institution of Environmental Health Sciences, NIEHS) presented a study from his laboratory on the role epigenetics and other microenvironment features on arsenic-induced carcinogenesis in stem cells. Their group's arsenic-induced cancer stem-like cells exhibit different extracellular vesicles compositions when compared to normal stem-like cells. Meanwhile, Fei Chen (Wayne State University) reported that chronic arsenic exposure induces malignant transformation in human bronchial epithelial cells and that some cells possess cancer stem-like properties. These arsenic-induced cancer stem-like cells had different cellular metabolism properties compared to embryonic stem cells. Specifically, these arsenic-induced cancer stem-like cells had increased levels of glycolysis intermediates, which are used for DNA and histone methylation. Furthermore, Lei Wang (University of Kentucky) found that arsenic-induced stem-cell like properties are associated with autophagy deficiency. Together these presentations provide evidence of the importance on the cancer stem-like cells in arsenic- 
related carcinogenesis. These presentations highlight that cancer stem cells are an important component of metal-induced carcinogenesis.

Autophagy-Autophagy serves as a stress adaptation and is a protective mechanism in certain circumstances. The identification of autophagy pathways have emerged in recent years and have proven to be an important mechanism in cancer development; recent studies show that these pathways play a role in metal-induced carcinogenesis (Wang L, et al., 2016). Specifically, the role of autophagy in arsenic-, cadmium-, $\mathrm{Cr}(\mathrm{VI})-$, and nickel-induced carcinogenesis is being investigated by multiple groups. Donna Zhang (University of Arizona) presented a mechanism for the disruption of autophagy; arsenic inhibits proper autophagy flux by interfering with the autophagosome-lysosome fusion. Eli Chapman (University of Arizona) revealed that p97 may be an important protein that links arsenic, autophagy and Nrf2, with malignant transformation.

There are an increasingly greater number of groups focusing attention on autophagy related proteins in metal carcinogenesis. Chuanshu Huang (New York University School of Medicine) found an upregulation of p62 expression in nickel-induced carcinogenesis, both in vivo and in vitro, and that p62 upregulation promotes cellular transformation and inflammation. Likewise, Zhuo Zhang (University of Kentucky) demonstrated that $\mathrm{Cr}(\mathrm{VI})$ induced transformation induces autophagy dysfunction that results from increased activation and expression of epidermal growth factor receptor (EGFR). Lei Wang (University of Kentucky) reported that an autophagy deficiency is crucial for the stabilization of p62, which leads to constitutively activated Nrf2 and promotes stem cell-like properties in arsenictransformed cells. These presentations highlight that dysfunction of autophagy plays a key role in metal-induced carcinogenesis.

Epigenetic Mechanisms of Metal Carcinogenesis-The role of metals on cellular epigenetics is another popular research area for investigations on the mechanisms of metalinduced carcinogenesis (Wang L, et al., 2016). Dazhong Xu (New York University School of Medicine) reported on the role of Gene 33/Mig6 in Cr(VI)-induced carcinogenesis. This group found that Gene 33/Mig6 is downregulated in $\mathrm{Cr}(\mathrm{VI})$-induced carcinogenesis and linked this downregulation to the DNA damage and genomic instability caused by this metal. Chunyuan Jin (New York School of Medicine) reported epigenetic changes induced by $\mathrm{Cr}(\mathrm{VI})$. Nuclear Protein 1 (Nupr1) was increased in the $\mathrm{Cr}(\mathrm{VI})$-induced carcinogenesis of lung cells due to the methylation and histone acetylation at its promotor. Also, Xixi Zhou (University of New Mexico) reported that $\mathrm{Cr}(\mathrm{III})$ interacts with acetylated histones by a binding interaction, which may involve histone protein modifications. $\mathrm{Cr}(\mathrm{VI})$ interacts with ribosomal DNA and can induce ribosomal DNA instability (Bernardo Lemos, Harvard University). $\mathrm{Cr}$ (VI) deregulates the proper Dlk-1-Dio3 genomic imprinting cluster (Zhishan Wang, University of Kentucky). In addition, Andrew Von Handorf (University of Cincinnati) suggests that chromium may disrupt chromatin topology and break chromatin structures.

Epigenetic mechanisms are not only involved in $\mathrm{Cr}(\mathrm{VI})$-induced carcinogenesis, but also other metal-induced diseases. Overexpression of key microRNAs play a role in arsenicinduced carcinogenesis via aneuploidy (Christopher States, University of Louisville). Arsenic also is able to induce changes of DNA methylation, binding patterns between 
acetylated histones, and gene regulatory regions across the genome of human urothelial cells (Xuefeng Ren, State University of New York at Buffalo). Yvonne Fondufe-Mittendorf (University of Kentucky) demonstrated that arsenic induces changes in the expression levels of histone H2B variants in human lung cells. Qin M. Chen (University of Arizona) found that histone deacetlyase changes protein translation following arsenic exposures. Nickel can induce epigenetic alterations in human lung cells, specifically resulting in increases in histone and DNA methylations (Max Costa, New York University, NY, USA). Nickel exposed human bronchial epithelial airway cells have altered histone modifications, epithelial-mesenchymal transition phenotypes, and increased gene expressions in proteins associated with epithelial-mesenchymal transition (Suresh Cuddapah, New York University School of Medicine). Taken together, these presentations firmly establish a role for epigenetic modifications as important mechanisms in metal-induced carcinogenesis.

Overall, it is known that oxidative stress, formation/function of stem-like cell, and processes associated with DNA damage and repair, autophagy and epigenetics all play a mechanistic role in metal-induced carcinogenesis. Oxidative stress was highlighted as a component mechanism involved with stem cells and autophagy. A comprehensive accounting of the steps in each of these processes known to induce carcinogenesis upon exposure to metals is not clear; additional studies are required.

\section{Metals in Diseases}

Investigating the effects of metals in cancers other than lung cancer continues to grow. Researchers also recognize the impact of heavy metal exposure on cohorts of human populations. There has also been growing interest on the role of heavy metals on a variety of maladies such as neuromuscular diseases, diabetes, and the immune system and on potential interactions with the microbiota.

Cancer-Although it is well established that heavy metals are carcinogenic, the exact molecular mechanisms are unclear and remain to be investigated (Wise et al., 2008; Wang L, et al., 2016). There are a growing number of reports on cancers, in addition to the wellestablished metal-induced lung cancer models. Maggie Louie (Dominican University) and Marcelo Bonini (University of Illinois at Chicago) investigate the potential role and impact of heavy metal exposure on the type and progression of breast cancers. Chendil Damodaran (University of Louisville) discussed studies at his laboratory on the relationship between heavy metal exposure and the development and mechanisms related to prostate cancer. Another group reported their findings on cadmium levels in prostate tumors and adjacent tissues in both African American and European American men (Neslund-Dudas Christine, Henry Ford Health System). The role of heavy metal exposure in kidney and bladder cancers is also being expanded. Scott Garrett (University of North Dakota) presented his in vitro models that show nephrotoxicity to the proximal tubule following exposure to cadmium. Seema Somji (University of North Dakota) reported that urothelial cells undergo neoplastic transformation following exposure to arsenic and cadmium, and that these transformed cells exhibited increases of specific carcinogenic genes compared to control cells. 
Cardiovascular-It has been reported that lead, arsenic, and cadmium exposures are linked to cardiovascular diseases and mortality (Burroughs Peña and Rollins, 2017). This area provides a newer set of disease endpoints for heavy metal exposures. There were multiple presentations on the role of arsenic exposure on cardiovascular diseases. Korren Mann (Lady Davis Institute, Canada) reported that the arsenic species As3MT (arsenite methyltransferase) is required for the development of arsenic-induced atherosclerosis. This report is of major importance as millions of individuals are exposed to arsenic in their drinking water and thus could be at higher risk for atherosclerosis. Similarly, Honglian Shi (University of Kansas at Lawrence) reported that through reactive oxygen species, arsenic causes endothelial cell injury, impairment to the endothelial permeability, and reduces blood flow. Taken together, these presentations suggest that arsenic exposure may lead to the development of cardiovascular diseases in populations across the globe that are exposed to arsenic. Since arsenic may induce cardiovascular diseases and complications via reactive oxygen species, other metals, such as chromium, could impact the development and progression of these cardiovascular diseases.

Diabetes-Although diabetes mellitus, specifically type II diabetes, is a significant health concern, the causes and risk factors are not well established. Some evidence indicates that metals may cause diabetes or similar effects (Chen et al., 2009). Two presentations discussed the role of cadmium in diabetes. Malek El Muayed (Northwestern University) reported that cadmium exposure induced dysfunction of beta cells in the pancreas of mice and produced physiological effects similar to type 2 diabetes mellitus. In addition, Jonathan Freedman (University of Louisville) reported that cadmium may disrupt insulin signaling and contribute to the development of diabetes. These presentations provide evidence that divalent metals such as cadmium, may contribute to the development of diabetes.

Neuromuscular-It has been established that mercury has detrimental neurologic effects (Rice et al., 2014), but its impacts on the neuromuscular systems are not fully understood; likewise there is limited data available on whether arsenic has negative neuromuscular impacts. Aaron Barchowsky (University of Pittsburgh) reported that arsenic impairs proper muscle development and muscle stem cell health. Matthew Rand (University of Rochester) reported that while methylmercury has other toxicity endpoints in addition to those previously reported, methylmercury specifically targets neuromuscular development. These two findings are important because they highlight neuromuscular complications from two different metals, and set the stage for more research investigating neuromuscular diseases in heavy metal-exposed populations, especially for pregnant women.

Immune System-The role of the immune system in heavy metal exposure, as well as the potential effects of heavy metals on the immune system and immune cells, continues to expand. Specifically, arsenic has been linked to impacts on the immune system (Dangleben et al., 2013). A variety of metals demonstrated to have impacts immune cells or immune system response. Both $\mathrm{Cr}(\mathrm{VI})$ and nickel can affect $\mathrm{T}$ cell function as reported by Gang Chen (University of Kentucky), and Shaodong Dai (University of Colorado). While, Britton Goodale (Dartmouth College) showed that low dose exposure to arsenic may impair the response of human bronchial epithelial cells to pathogenic bacteria and could increase 
susceptibility to bacterial lung infections in arsenic-exposed populations. Preconception exposure to cadmium in mice altered DNA methylation patterns in sperm, and this exposure was found to alter genes associated with the immune system (John Barnett, West Virginia University). Early data from a cohort study in Bangladesh (health effects of arsenic longitudinal study (HEALS), suggests that adults and children exposed to arsenic are at a higher risk for respiratory infections, such as tuberculosis (Muhammad Parvez, Columbia University). These studies suggest that metals can affect immune system health.

The recent studies on the relationship between metal exposure and diseases firmly establish a role for metals in multiple diseases apart from cancer, including cardiovascular diseases, diabetes, neuromuscular disorders, and impairment of the immune system. A causal relationship between a specific disease and a specific metal has not been established. However, it is also important to investigate any potential role of heavy metals in the prevention and treatment of different diseases. Teresa Fan (University of Kentucky) found that some selenium compounds have anti-cancer effects in vitro and ex vivo, which suggests that some selenium compounds could be used as anti-cancer compounds.

\section{Air Pollution of Metal Particles and Health}

Airborne particles and air pollution have long been associated with diseases and cancer (Burroughs et al, 2017). Metals are known to cause cancer via inhalation exposure (Fay et al., 2005; Chou et al., 2007; Wise et al., 2008; Faroon et al., 2012; Wilbur et al., 2012; Wang L, et al., 2016). Inhalation of "real world" arsenic-containing dusts disrupted normal development of mouse lungs and altered the mouse pulmonary structure and function (Clark Lantz, University of Arizona). In addition, it was reported that urban city air, which contains a relatively high amount of transition metals, could induce cardiopulmonary dysfunctions (Alex Carll, University of Louisville). Exposure to ambient particulate matter ( $\left.\mathrm{PM}_{2.5}\right)$ from industrial sites in the Midwest caused cardiovascular dysfunctions in rats (James Wagner, Michigan State University). Mice exposed to air containing uranium and vanadium (from a uranium mine site in Arizona) had pulmonary and vascular endothelial dysfunctions (Matthew Campen, University of New Mexico).

\section{Perspectives on Future Research \\ Autophagy and autophagy deficiency}

As discussed above, there are multiple groups investigating the role of autophagy in metalinduced carcinogenesis. Observed autophagy deficiencies include: blockage of autophagy flux, lysosome biogenesis inhibition, and inhibition of lysosome and autophagysome fusion. Autophagy deficiencies appear to play an important role in metal-induced carcinogenesis. Some autophagy related proteins such as p62, Nrf2, and HIF-1a are a hot topic in both cancer studies and in metal carcinogenesis. Previous studies have revealed a role and mechanism of autophagy in carcinogenesis and have proven to be very helpful on understanding health concerns of environmental metal exposures (Son et al., 2014). 


\section{Metabolic Reprogramming}

Metabolic reprogramming is a now considered a hallmark of cancer (Hanahan and Weinberg, 2011) and there is a growing body of literature to support its role in tumorigenesis. However, there is limited literature to show whether metabolic reprogramming has an early role in carcinogenesis (Beloribi-Djefaflia et al., 2016). Therefore, additional investigations on metal-induced metabolic reprogramming are necessary. During the conference there were reports that $\mathrm{Cr}(\mathrm{VI})$, arsenic, and other metals may alter cellular energetics, such as lipid metabolism (James Wise, University of Kentucky). We expect that this area of research will be expanded in the future.

\section{Role of the Microbiomes}

The role of the microbiome is a rapidly growing field. It is important for a variety of diseases such as neurological diseases, digestive diseases, and obesity (Woting and Blaunt, 2016). However, its role in metal toxicity and the health impacts of heavy metals is poorly understood. Scott Burchiel (University of New Mexico) found that children of arsenicexposed mothers had significant changes in bacterial populations of their upper airway microbiome associated with increased levels of Streptococcus. This finding suggests that heavy metals may impact microbiomes. We expect that this area will continue to expand in the field of metal toxicity and carcinogenesis considering the prevalence and importance of the various microbiomes in the human body and their impact on disease development.

\section{Metal Exposure and Other Factors}

In the environment, heavy metal exposure usually occurs along with other factors. The carcinogenic functions of the metals could interact with those non-metal factors to produce synergistic or additive affects. Honglian Shi (University of Kansas) discussed the coexposure of arsenic with ethanol. Previous reports showed that alcohol consumption has a synergistic effect with arsenic on promotion cancer development (Wang et al., 2015). As another example, it was reported that ultraviolet radiation in combination with arsenic exposure has synergistic functions on skin carcinogenesis (Cooper et al., 2009). Therefore, it is important to determine if there are synergistic or additive effects caused by exposure to multiple metals and to investigate the interactive effects of metals and other carcinogens or nutritional factors.

\section{Reproductive Health}

It has been reported that arsenic exposure impacts child health and development (Winterbottom et al., 2015). Sarah E. Rothenberg (University of South Carolina) presented her study on effects of maternal methylmercury exposure on offspring neurodevelopment. Offspring of mothers, who ingested rice containing a high level of mercury in rural china, had decreased cognition. This study raises an important a health issue in communities relying on rice as their main food source. Studies suggest that arsenic exposure can lead to reproductive problems (Wang X, et al., 2016; Susko et al., 2017). The effect of environmental metal exposure on mental and reproduction requires additional attention. 


\section{Summary}

Overall, the $9^{\text {th }}$ Conference on Metal Toxicity and Carcinogenesis was a successful one. The presenters updated their key findings in the field concerning the mechanisms of metal carcinogenesis, the role of metals in different diseases, and the impact of airborne particles on health. Insights were provided on emerging research areas in the field. There was a brief career development session aimed at providing young investigators, post-doctoral fellows, and other students with valuable advice on career development in the environmental health and science research field from established, senior scientists in the field of metal toxicity and carcinogenesis.

It is well known that heavy metals such as arsenic, cadmium, $\mathrm{Cr}(\mathrm{VI})$, and nickel cause cancer. Still, a comprehensive understanding of the mechanisms that promote these effects remain elusive. In a recent review, we highlight some of the mechanisms involved in heavy metal carcinogenesis such as: oxidative stress, apoptosis, angiogenesis, genomic instability, generation/function of cancer stem cells, inflammation, and epigenetic alterations (Wang L, et al., 2016). During this meeting, these mechanisms were discussed in depth. As an outcome, knowledge-based mapping of pathways may expand our understanding of pathway interactions of metal-induced carcinogenesis and diseases. The meeting also highlighted the importance of understanding how metals are involved in diseases besides cancer. Specifically, metals influence neuromuscular diseases, breast cancer, bladder cancer, diabetes, muscular disorders, and immune system effects. Human cohort exposures for these other diseases were also discussed. We expect to see more data from these cohort studies in the future.

Additional research and a deeper understanding of the role altered energy metabolism has on metal-induced carcinogenesis is anticipated given its therapeutic importance in cancer treatment and cancer development. On the same note, we expect investigations on the role of the microbiomes in metal toxicity and carcinogenesis to expand. Lastly, research on reproductive health and early life exposures is sure to grow in the next few years as well. The conference was documented in a special issue of the journal of Toxicology and Applied Pharmacology, highlighting in greater detail the research presented.

\section{Acknowledgments}

We would like to thank Terry Keys from the University of Kentucky technical and administrative support in running the conference. We would also like to thank the Markey Cancer Center's Research Communications Office for their critical review of this manuscript. The 9th Conference on Metal Toxicity and Carcinogenesis was supported by a conference grant from the NIH/National Institute for Environmental Health Sciences [R13 ES027336-01], and by the University of Kentucky's Markey Cancer Center, University of Kentucky Office of Vice President for Research and the University New Mexico's College of Pharmacy, Health Sciences Center.

\section{References}

Beloribi-Djefaflia S, Vasseur S, Guillaumond F. Lipid metabolic reprogramming in cancer cells. Oncogenesis. 2016; 5:e189. [PubMed: 26807644]

Beyersmann D, Hartwig A. Carcinogenic metal compounds: recent insight into molecular and cellular mechanisms. Arch Toxicol. 2008; 82:493-512. DOI: 10.1007/s00204-008-0313-y [PubMed: 18496671] 
Bower, JJ., Leonard, SS., Shi, X. Mol Cell Biochem. Kluwer Academic Publishers; 2005. p. 3-15.Conference overview: molecular mechanisms of metal toxicity and carcinogenesis

Burroughs Peña MS, Rollins A. Environmental Exposures and Cardiovascular Disease: A Challenge for Health and Development in Low- and Middle-Income Countries. Cardiol Clin. 2017; 35(1):7186. [PubMed: 27886791]

Chen YW, Yang CY, Huang CF, et al. Heavy metals, islet function and diabetes development. Islets. 2009; 1(3):169-76. [PubMed: 21099269]

Chou, S., Harper, C., Ingerman, L., et al. Toxicological Profile for Arsenic. Agency for Toxic Substances and Disease Registry (US); Atlanta, GA: 2007.

Cooper KL, Liu KJ, Hudson LG. Enhanced ROS production and redox signaling with combined arsenite and UVA exposure: contribution of NADPH oxidase. Free Radic Biol Med. 2009; 47(4): 381-8. [PubMed: 19414066]

Dangleben NL, Skibola CF, Smith MT. Arsenic immunotoxicity: a review. Environ Health. 2013; 12(1):73. [PubMed: 24004508]

Faroon, O., Ashizawa, A., Wright, S., et al. Toxicological Profile for Cadmium. Agency for Toxic Substances and Disease Registry (US); Atlanta (GA): 2012.

Fay, M., Wilbur, S., Abadin, H., et al. Toxicological Profile for Nickel. Agency for Toxic Substances and Disease Registry (US); Atlanta (GA): 2005.

Hanahan D, Weinberg RA. Hallmarks of cancer: the next generation. Cell. 2011; 144(5):646-74. [PubMed: 21376230]

Koedrith P, Seo YR. Advances in carcinogenic metal toxicity and potential molecular markers. Int J Mol Sci. 2011; 12:9576-9595. DOI: 10.3390/ijms12129576 [PubMed: 22272150]

Leonard SS, Bower JJ, Shi X. Metal-induced toxicity, carcinogenesis, mechanisms and cellular responses. Mol Cell Biochem. 2004; 255:3-10. [PubMed: 14971640]

Rice KM, Walker EM Jr, Wu M, et al. Environmental mercury and its toxic effects. J Prev Med Public Health. 2014; 47(2):74-83. [PubMed: 24744824]

Son YO, Pratheeshkumar P, Roy RV, et al. Nrf2/p62 signaling in apoptosis resistance and its role in cadmium-induced carcinogenesis. J Biol Chem. 2014; 289(41):28660-75. [PubMed: 25157103]

Susko ML, Bloom MS, Neamtiu IA, et al. Low-level arsenic exposure via drinking water consumption and female fecundity - A preliminary investigation. Environ Res. 2017; 154:120-125. [PubMed: 28061371]

Wang L, Chen F, Zhang Z, et al. Cancer stem cells in the mechanism of metal carcinogenesis. J Environ Pathol Toxicol Oncol. 2012; 31(3):245-63. [PubMed: 23339699]

Wang L, Hiltron JA, Wise JTF, et al. Ethanol enhances arsenic-induced cyclooxygenase-2 expression via both NFAT and NF- $\kappa$ B signaling in colorectal cancer cells. Toxicol Appl Pharmacol. 2015; 288(2):232-239. [PubMed: 26220687]

Wang L, Wise JTF, Zhang Z, et al. Progress and prospects of free radicals in metal-induced carcinogenesis. Curr Pharmacol Rep. 2016:1-9. [PubMed: 27088072]

Wang X, Zhang J, Xu W, et al. Low-level environmental arsenic exposure correlates with unexplained male infertility risk. Sci Total Environ. 2016; 571:307-13. [PubMed: 27485131]

Wang S, Shi X. Molecular mechanisms of metal toxicity and carcinogenesis. Mol Cell Biochem. 2001; 222(1-2):3-9. [PubMed: 11678608]

Wilbur, S., Abadin, H., Fay, M., et al. Toxicological Profile for Chromium. Agency for Toxic Substances and Disease Registry (US); Atlanta (GA): 2012.

Winterbottom EF, Fei DL, Koestler DC, et al. GLI3 links environmental arsenic exposure and human fetal growth. EBioMedicine. 2015; 2(6):536-43. [PubMed: 26288817]

Wise SS, Holmes AL, Wise JP Sr. Hexavalent chromium-induced DNA damage and repair mechanisms. Hexavalent chromium-induced DNA damage and repair mechanisms. Rev Environ Health. 2008; 23(1):39-57. [PubMed: 18557597]

Woting A, Blaut M. The intestinal microbiota in metabolic disease. Nutrients. 2016; 8(4):202. [PubMed: 27058556] 
Zhou X, Burchiel SW, Hudson LG, et al. Conference Summary and Recent Advances: the 8th Conference on Metal Toxicity and Carcinogenesis. Biol Trace Elem Res. 2015; 166(1):1-6. [PubMed: 25975949] 


\section{Highlights}

- An overview of the $9^{\text {th }}$ Conference on Metal Toxicity and Carcinogenesis.

- $\quad$ Current progress on mechanisms of metal-induced health concerns.

- $\quad$ Prospective areas for future studies for the metal toxicity and carcinogenesis. 